\title{
Patient characteristics affecting attendance at general outpatient clinics
}

\author{
R J McClure, S J Newell, S Edwards
}

\begin{abstract}
A study was carried out to identify the characteristics of children who do not attend appointments at general outpatient clinics. Over six months, 359 children who had an appointment at a general clinic were studied using a questionnaire given to parents (74\% response rate) and by inspection of case notes. Based on their first appointment in the study period, children were divided into 'attenders' $(n=262)$ and 'non-attenders' ( $n=97$ ) for analysis. Nonattenders were significantly more likely to have one or more of the following characteristics: lower social class, poorer housing, unmarried parent(s) $(56 \%$ v $33 \%)$, longer journey to clinic (35 $v$ 27.6 minutes), more appointments per year (4.2 $v 3.3)$, poorer past attendance record, and received their appointment by post $(76 \%$ $v 44 \%$ ). Surprisingly parents of nonattenders rated their children to have a significantly more severe illness than those who attended. These results suggest that attendance is primarily determined by social and logistical factors as well as appointment details, rather than illness severity.

(Arch Dis Child 1996; 74: 121-125)
\end{abstract}

Keywords: outpatient clinics, patient compliance, hospital organisation and administration.

Non-attendance at outpatient clinics is a common occurrence. ${ }^{1-3}$ It can be particularly troublesome in general clinics but is felt by many paediatricians to be an inevitable, if frustrating, phenomenon. Apart from the obvious concern that some children do not receive the medical attention that has been judged necessary, it results in a waste of time and resources.

Our hospital, in common with most large inner city hospitals, suffers particularly in this respect. Routinely collected data from our general outpatient clinics have consistently shown a non-attendance rate in excess of $27 \%$. Review of the literature reveals surprisingly few studies on the reasons behind non-attendance and almost all relate to adult practice in the USA. Few studies have been carried out in our health service. It has been suggested that in the UK this may be due to the different financial consequences of non-attendance, at least to doctors! ${ }^{4}$ Two notable studies have been carried out on general clinics, by Cooper and Lynch and Andrews et al but both involved relatively small numbers of 100 and 46 children respectively. 56
We undertook a prospective study of this problem concentrating on the identification of factors, related directly to the child and his or her family, that may affect the decision to attend or not. It is widely held that children do not attend because their problem is perceived to be less severe, or has resolved. We felt that this hypothesis should be tested also.

\section{Study population and method}

STUDY POPULATION

Initially we determined the non-attendance rates for the broad spectrum of general and specialty clinics at St James's University Hospital which serves the eastern area of Leeds, as well as being a tertiary referral centre for many specialties. This was achieved by recording, for a period of two months, the nonattendance rate of the seven general clinics and the 46 specialty clinics that take place weekly. This showed a mean (SD) non-attendance rate of $25(9.5) \%$ for general clinics and 27 $(19 \cdot 1) \%$ for specialty clinics. This is similar to the non-attendance rate of $25 \%$ quoted by Cooper and Lynch at Guy's Hospital, London. ${ }^{5}$

We studied the general clinic with the nonattendance rate nearest the mean. This clinic, held weekly, sees both newly referred children and those for review. The clinic is staffed by a consultant paediatrician and a paediatric registrar as well as appropriate support staff of nurses and ancillary staff.

We included prospectively in the study all children who had appointments for this clinic during the six month period of 1 August 1992 to 31 January 1993.

METHOD

Before each clinic the notes of each child who was due their first appointment in the study period, irrespective of whether this was their first ever appointment or not, were inspected by a paediatric registrar (RM). He was not involved in seeing any patients and at this time it was not known whether they would attend the clinic or not. Data were also collected using a questionnaire designed for the study. The questionnaire was divided into sections recording details concerning the child's previous record and length of attendance at that clinic, social class (assessed using the definition of the registrar general with the unemployed included, for the purposes of this study, in social class 5) and miscellaneous factors such as the child's growth parameters. In addition the investigator made an estimation of the severity of the child's main illness using a linear 
Figure 1 Mean (with 95\% confidence limits) illness severity score given by parents and the investigator.

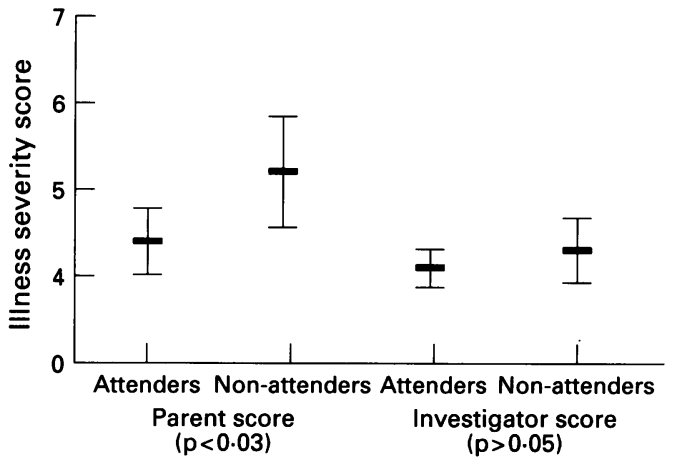

analogue score, increasing from 1 to 10 . To provide illustration, children suffering epilepsy were scored from 2 (excellent long term seizure free control) to 9 (frequent seizures each day with accompanying learning difficulty).

On the attending child's arrival at clinic, their accompanying adult (usually the mother) was asked to complete and then return a separate second questionnaire, unsupervised and unaided, while they waited. This questionnaire was broadly divided into sections about the child and his illness, details of their family and social circumstances, the logistical aspects of their attendance, and finally their experiences of and satisfaction with their appointment. Parents were asked to choose their answer to most questions from mutually exclusive options. The questionnaire finally asked the parent to estimate the severity of their child's main illness using an identical scoring system to that described above.

During the next two weeks a paediatric health visitor (SE) attempted to visit at home each family of children who had not attended their first appointment in the study period. Parents were asked to complete the same questionnaire as that given to those of attending children. For certain questions where it was applicable they were asked to give their answers based on their last visit to clinic. Again supervision and assistance were avoided if possible.

Therefore data consisted ideally of one questionnaire completed by the registrar (RM) and one completed by the family for each child in the study. Children were allocated into two groups for analysis - those 'attending' and those 'non-attending', depending upon their attendance at their first appointment during the study period. All

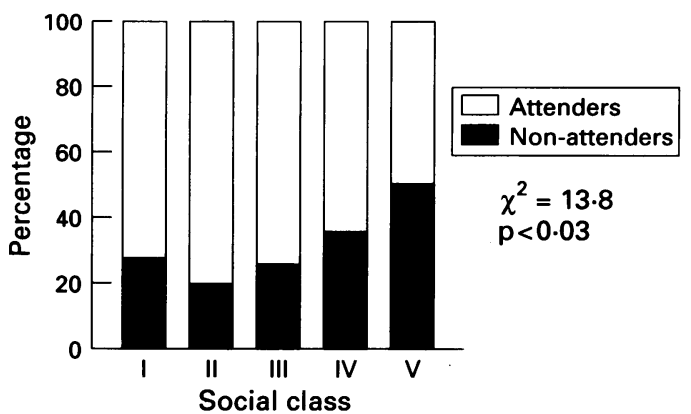

(N) (16) (36) (85) (53) (52)

Figure 2 Percentage of attending and non-attending children within each social class. patients were analysed as a whole and the results are expressed as such, unless stated specifically. No distinction was made between new referrals and those who had been seen previously. Statistical tests used to compare groups included the $\chi^{2}$ test, Fisher's exact test, Student's $t$ test, and Spearman's correlation test. Ethical approval was given by the local research ethics committee.

\section{Results}

The total number of eligible children in our study group was 359 . All had a questionnaire completed from the notes. We successfully offered a questionnaire to over $90 \%$ of families; $267(74 \%$ of the total) of the questionnaires were satisfactorily completed and returned for analysis. Fifteen families were from a minority ethnic group, all of whom had at least one English speaking family member. All 15 completed the questionnaire. Of the 359 patients, 129 were 'new patients' and 230 were 'review patients'.

The total number of children in the attending group was 262 of which 195 (74\%) completed questionnaires. Overall there were 97 children who did not attend giving a nonattendance rate of $27 \%$. The same proportion of non-attenders satisfactorily completed questionnaires, that is 72 out of $97(74 \%)$.

Analysis revealed significant differences in the following variables between those who attended and those who did not:

AGE

Attending children were younger, with a mean (SD) age of $64(3.3)$ months compared with $78(6.4)$ months for those not attending $(\mathrm{p}<0.04)$.

\section{ILLNESS SEVERITY (SEE FIG 1)}

Parents or carers of those attending rated the severity score of their child's illness as 4.4 $(0 \cdot 19)$. The parents or carers of non-attending children perceived their children's illness as significantly more severe, with a mean severity score of $5.2(0.32)(p<0.03)$. The doctor also rated the scores of the attending children lower, at $4 \cdot 1(0 \cdot 11)$, compared with $4 \cdot 3(0 \cdot 18)$, but this was not significant. The rank Spearman's correlation coefficient between the scores that the carer and the doctor gave was $0.4(p<0.01)$.

\section{SOCIAL CHARACTERISTICS}

Social class (see fig 2)

Analysis showed a difference in the distribution in social class of the two groups $\left(\chi^{2}=13 \cdot 8\right.$, $\mathrm{p}<0.03)$. This was due to a larger proportion of families who did not attend being from social classes 4 and 5.

\section{Marital status (see table 1)}

Non-attending children had parents with a different marital status distribution from attending children $\left(\chi^{2}=12 \cdot 9, \mathrm{p}<0 \cdot 005\right)$. Although 
Table 1 Marital status and type of dwelling of attending and non-attending patients; values are number (\%)

\begin{tabular}{|c|c|c|c|c|c|c|c|c|}
\hline \multirow[b]{2}{*}{ Attendance } & \multicolumn{4}{|c|}{ Marital status ${ }^{\star}$} & \multicolumn{4}{|c|}{ Type of dwelling child lives in $\star \star \star$} \\
\hline & Married & Cohabiting & Single & Other & Detached & Semidetached & Terraced & Other \\
\hline $\begin{array}{l}\text { Attenders }(n=195) \\
\text { Non-attenders }(n=72)\end{array}$ & $\begin{array}{r}131(67) \\
32(44)\end{array}$ & $\begin{array}{l}9(5) \\
9(13)\end{array}$ & $\begin{array}{l}31(16) \\
17(24)\end{array}$ & $\begin{array}{l}24(12) \\
14(19)\end{array}$ & $\begin{array}{c}38(19) \\
3(4)\end{array}$ & $\begin{array}{l}87(45) \\
34(47)\end{array}$ & $\begin{array}{l}39(20) \\
22(31)\end{array}$ & $\begin{array}{l}31(16) \\
13(18)\end{array}$ \\
\hline
\end{tabular}

${ }^{\star} \chi^{2}=12 \cdot 9, \mathrm{p}<0.005 ;{ }^{\star \star} \chi^{2}=10 \cdot 8, \mathrm{p}<0 \cdot 02$.

there were fewer single or cohabiting parents among the attending families, this difference was mostly due to a much larger percentage of married parents in this group $(67 \% v$ $44 \%)$.

Type of dwelling (see table 1)

A larger proportion of children who did not attend lived in terraced houses (by far the commonest low cost housing in Leeds), flats, or maisonettes. Attending patients were more likely to live in detached or semidetached housing $\left(\chi^{2}=10 \cdot 8, \mathrm{p}<0.02\right)$.

\section{LOGISTICAL FACTORS (SEE TABLE 2)}

Type of transport used

There was a difference $\left(\chi^{2}=13.7, \mathrm{p}<0.002\right)$ in the modes of transport used to reach the clinic (non-attending families were asked how they would have travelled if they had come). This was mainly due to a much higher proportion of attending children coming by car $(63 \%)$, compared with those non-attending $(37 \%)$ who tended to use public transport or walked.

\section{Distance and time to clinic}

There was no significant difference in the mean distance in miles travelled to the clinic but there was, however, a difference in the journey time from home to the clinic $(p<0.006)$. The mean (SD) time travelled by the attending group was $27 \cdot 6(1 \cdot 16)$ minutes which was considerably less than the $35(2 \cdot 96)$ minutes for the non-attending group. Those few who had never attended were asked to estimate their journey time. Lack of numbers from individual areas precluded analysis looking for any geographical clustering.

Table 2 Logistical factors; values for type of transport used are number (\%)

\begin{tabular}{|c|c|c|c|c|c|}
\hline \multirow[b]{2}{*}{ Attendance } & \multicolumn{3}{|c|}{ Type of transport used ${ }^{\star}$} & \multirow{2}{*}{$\begin{array}{l}\text { Mean }(S D) \\
\text { distance } \\
\text { to clinic }{ }^{\star \star}\end{array}$} & \multirow{2}{*}{$\begin{array}{l}\text { Mean (SD) } \\
\text { time to } \\
\text { clinic }\end{array}$} \\
\hline & Car & Public transport & Other & & \\
\hline $\begin{array}{l}\text { Attenders }(n=195) \\
\text { Non-attenders }(n=72)\end{array}$ & $\begin{array}{r}122(63) \\
27(37)\end{array}$ & $\begin{array}{l}59(30) \\
38(53)\end{array}$ & $\begin{array}{l}14(7) \\
7(10)\end{array}$ & $\begin{array}{l}4 \\
4\end{array}$ & $\begin{array}{l}27 \cdot 6(1 \cdot 16) \\
35(2 \cdot 96)\end{array}$ \\
\hline
\end{tabular}

${ }^{\star} \chi^{2}=13 \cdot 7, \mathrm{p}<0.002 ;{ }^{\star \star} \mathrm{p}>0.05 ;{ }^{\star \star \star} \mathrm{p}<0.006$

Table 3 Appointment related factors

\begin{tabular}{llll}
\hline Attendance & $\begin{array}{l}\text { Mean (SD) of appointments } \\
\text { in previous year }\end{array}$ & $\begin{array}{l}\text { Previously attended } \\
\text { appointment }(\%)^{\star \star}\end{array}$ & $\begin{array}{l}\text { Appointments received } \\
\text { by post }(\%)^{\star \star \star}\end{array}$ \\
\hline Attenders $(\mathrm{n}=262)$ & $3 \cdot 3(0 \cdot 14)$ & 85 & 44 \\
Non-attenders $(\mathrm{n}=97)$ & $4 \cdot 2(0 \cdot 26)$ & 55 & 66
\end{tabular}

${ }^{\star} \mathrm{p}<0.002 ;{ }^{\star \star} \chi^{2}=35 \cdot 7, \mathrm{p}<0.0001 ;{ }^{\star \star \star} \chi^{2}=13.8, \mathrm{p}<0.001$.
APPOINTMENT RELATED FACTORS (SEE

TABLE 3)

Method of receiving appointment

The physical method of giving the appointment to the patient's family appear to affect future attendance. Children who had not attended their previous appointment and 'new' patients were excluded from this analysis, as appointments had to be posted. Among attending children, $56 \%$ had received their next appointment personally at their previous appointment, leaving $44 \%$ who, for various reasons, were sent their next appointment by post. This compared with $76 \%$ of the nonattending patients who received their appointment by post $\left(\chi^{2}=13 \cdot 8, \mathrm{p}<0 \cdot 001\right)$.

\section{Number of appointments in last 12 months}

The attending patients had fewer mean (SD) appointments in the previous 12 months with $3.3(0 \cdot 14)$ compared with $4 \cdot 2(0 \cdot 26)$ appointments for the non-attending group $(p<0.002)$.

\section{Previous attendance record}

In the attending group 223 patients $(85 \%)$ had attended their last appointment compared with only $53(55 \%)$ in the non-attending group $\left(x^{2}=35 \cdot 7, \mathrm{p}<0 \cdot 0001\right)$. These data were collected from the whole study population because information was collected directly from the notes.

The factors studied that did not determine attendance were: sex distribution, weight, height, the main carer, the proportion of families in which the mother worked, parental ages, number of siblings, parents' views of the clinic in terms of their previous satisfaction or understanding of events, or in the mean length of time that patients had actually been on the clinic list.

\section{Discussion}

This study has shown that attendance at general paediatric clinics is principally influenced by the following factors: social (as shown by differences in the interacting factors of social class, type of housing, and the parent's marital status); logistical (mode of transport and the time taken to travel to clinic); and those related to the appointment itself (method of receiving the appointment, number of appointments per year, and previous attendance record).

Surprisingly the parent's perception of the severity of their child's illness does not appear to be a major factor as shown by the higher illness severity scores given to the non-attending 
children by their parents. The higher mean score given to non-attending children by the medical assessment, while not reaching significance, does lend some weight to this interpretation. No attempt was made to formally validate the method used to quantify illness severity but some indication of its reliability was shown by the significant positive correlation between the scores given by the doctor and the parents.

The above findings suggest that paediatricians have been interpreting and dealing with non-attendance inappropriately. Nonattendance is not because children are less ill but because of difficulties associated with the factors above. Discharge based simply on nonattendance does these children a considerable disservice. This is particularly true when young children are involved as it is not they who make the decision whether to attend.

Our finding of the effect of socioeconomic factors on attendance confirms only some of the findings of Cooper and Lynch. ${ }^{5}$ This may be because their study involved children who persistently did not attend. The overriding effect of social and logistical factors as well as details of the appointment itself, on parents decision to attend or not, rather than the severity of the child's illness has not been shown before.

Apart from the cost to patients, non-attendance causes the loss of valuable resources (both financial and personnel) that could be used elsewhere. Our own hospital's best estimate for the actual financial cost of each appointment not attended is $£ 20-£ 40$.

Paediatricians can do relatively little to improve the social disadvantages of most nonattending children. This is the work of government. Changes can be made though to clinic organisation and logistical problems can often be alleviated at relatively low cost. An example of a beneficial change is to start to personally give a child's next appointment to parents as they leave the clinic, rather than use the post. Probable reasons why posting results in lower attendance include incorrect addressing and the loss of opportunities to agree with parents appointment times that are convenient. When posting is unavoidable, the format may be improved by using more familiar language, tear off cancellation slips which are simple to fill in, prepaid reply envelopes (surprisingly inexpensive!), and even the use of white rather than brown, bill-like envelopes. A direct line telephone number may also be helpful.

The finding that poor attendance was associated with more frequent appointments suggests that parents do not wish to attend as often as doctors feel appropriate. Attendance may improve if less frequent appointments negotiated between paediatrician and parent are made. It is better to see children less frequently than not at all! Home visits by other health workers have also been shown to be effective in improving attendance. ${ }^{3}$

Logistical problems may be reduced by judicious use of hospital taxis or buses, improving parking facilities, and the use of outreach clinics. The latter, more radical, option would reduce travel difficulties and may be best targeted to areas of poor socioeconomic status where the non-attendance rate is often high. Local health centres that are familiar to families would provide suitable accommodation for such clinics.

Accurate prediction of non-attendance is a hitherto unexplored area. Future planning and targeting of resources will require this and will be of benefit to patients and hospitals. Better spacing of appointment times of those more likely to attend would help to avoid clustering. Prediction may be possible using data like these and Neural Net computer software. Preliminary attempts using this technique have allowed us to correctly identify a child who will not attend with a moderately high degree of accuracy. We have recently reported this ${ }^{7}$ and intend further study in the future.

Non-attendance is a complex issue. The child's general practitioner, ${ }^{8-12}$ clinical facilities, and the interaction between the hospital practitioner and the family ${ }^{13}$ are all important and require further study.

In summary, our findings suggest that social, logistical, and actual appointment details are the predominant factors that influence families' decision to attend general outpatient clinics. The parents perception of their child's illness is of lesser importance. We have found no evidence to suggest that nonattendance means that disease is absent. Discharging a child on this basis can not be recommended. We believe that our findings suggest several ways that non-attendance may be reduced.

Dr Robert McClure is currently a clinical research fellow in neonatal medicine and is generously supported by the Nutricia Research Foundation. We thank all the parents and children who participated in this study. We are also grateful to Professor who participated in this study. We are also grateful to Professo S R Meadow, Dr J T Brocklebank, Dr D Fielding, outpatien nursing staff, medical record officers, Mrs P Atkinson of the medical audit department, and Mrs A Monaghan the paediatric operations manager of St James's University Hospital Trust. Funding for the study was generously provided by the Patient's
Charter Trust.

1 Jones DT. A survey of hospital outpatient referral rates, Wales, 1985. BMF 1987; 295: 734-6.

2 McGlade KJ, Bradley T, Murphy GJ, Lundy GPP. Referrals to hospitals by general practitioners: a study of compliance and communication. BMF 1988; 297: compliance

3 Anderson FP, Rowe DS, Dean VC, Arbisser A. An approach to the problem of non-compliance in a paediatric outpatient clinic. Am f Dis Child 1971; 122: 142-3.

4 Frankal $S$, Farrow A, West $R$. Non-attendance or noninvitation? A case control study of failed outpatien appointments. BMF 1989; 298: 296-8.

5 Cooper N, Lynch M. Lost to follow-up. Arch Dis Child 1979; 55: 765-9.

6 Andrews R, Morgan JD, Addy DP, McNeish AS Understanding non-attendance in outpatient paediatric clinics. Arch Dis Child 1990; 65: 192-5.

7 Snowden S, Weech P, McClure RJ, Smye SW, Dear PRF. A neural network to predict attendance of paediatric patients at outpatient clinics. Neural Computing and Applications 1995; 3: 100-5.

8 Director of Public Health. Annual report of director of public health 1990-91. London: Department of Health, 1991.

9 Cybulska E, Rucinski J. Communication between doctors. Br f Hosp Med 1989; 41: 266-8.

10 Stanley I. Communication between general practice and hospital. The Practitioner 1987; 231: 1051-5.

11 Grace JF, Armstrong D. Reasons for referral to hospital: extent of agreement between the perceptions of patients,
general practitioners and consultants. Fam Pract 1986; 3: general

12 Cockburn J, Gibberd RW, Reid AL, Sanson-Fisher RW. Determinants of non-compliance with short term antiDeterminants of non-compliance with
biotic regimens. BMF 1987; 295: 814-8.

13 Shar CP, Macbride JR, Laril GA. Appointment systems: why does a patient not return? Can $\mathcal{F}$ Public Health 1977; 68: $148-53$. 